\title{
Research on the Difficulties and Strategies of Chinese Traditional Culture Communication in Foreign Languages Universities against the backdrop of Internationalization
}

\author{
Yong $\mathrm{Wu}$ \\ Zhejiang Yuexiu University of Foreign Languages \\ Shaoxing, Zhejiang, China \\ 704991373@qq.com
}

\author{
Abdul Jalil Othman and Mohd Rashid Mohd Saad \\ Faculty of Education University Malaya, Kuala Lumpur, \\ Malaysia
}

\begin{abstract}
This paper mainly aims to explore the current situation of Chinese traditional culture in foreign language universities with the development of internationalization. By concluding these three aspects of the characteristics of traditional Chinese culture, mainly the ignoring, neediness and Integration, the author find out three aspects of obstalce: The Dissemination of Traditional Culture in Foreign Language Textbooks, The cultural awareness of the situation of Students and Teachers and Traditional culture in foreign languages testing. These obstacles have affected the Chinese traditional culture in the foreign language colleges in the context of internationalization, so that can put forward to optimize the strategy of traditional culture communication in foreign language colleges, such as Teachers to cultivate the direction, Teaching content adjustment and Communication means change.
\end{abstract}

Keywords-Chinese Traditional Culture Communication; internationalization; difficulties; strategies

\section{INTRODUCTION}

General Secretary Xi Jinping pointed out: "Our nation is a great nation in the five thousand years of civilization development process, the Chinese nation for the progress of human civilization made an indelible contribution." In many occasions, many times he mentioned that "the Chinese traditional culture is our deepest soft power." The Ministry of Education has also issued "to improve China's outstanding traditional culture and education guidance", calling for the strengthening of traditional culture and education [1].

With the internationalization of the process of accelerating, the world more and more closely linked, the SinoWestern cultural exchanges and conflicts continue to strengthen. In this situation, colleges and universities, especially as foreign language institutions, become the frontier positions with national culture and education exchange. How to carry forward the excellent traditional Chinese culture, how to melt the "international "with the "localization "effectively, and how to do" foreign language professional international school "two-way model are worth exploring the subjects. In addition, the universities have some inescapable responsibilities and obligations of personnel training, the behavior of students, the shape of students characters, and the cultivation of values. Therefore [2], how to strengthen the outstanding traditional Chinese culture in college students, and enhance cultural selfconfidence is an unavoidable important issue.

\section{THE CHARACTERISTICS OF TRADITIONAL CHINESE CULTURE COMMUNICATION IN FOREIGN LANGUAGES UNIVERSITIES}

\section{A. Ignoring}

For a long time, the bias in China's foreign language education has led to and increased the lack of students' national cultural identities. In terms of the guiding ideology of English education, from the revision of the nine-year compulsory education, full-time junior high school English education program to the syllabus of English majors in colleges and universities, the humanities of the English-speaking countries, such as geography [3], history, culture Traditions and customs and so on were put on the important role. "National English Curriculum Standards" clearly put forward the purpose of cultural teaching in English teaching is to accumulate the knowledge of English culture, cultivate cross-cultural communication and communication skills. Therefore, the input of the target language culture in the current English education has gradually become the consensus of the English language. Once the cultural input in English education is mentioned, most English educators believe that the target language culture is the input of Anglo-American culture rather than the Chinese culture.

But as the main body of the cultural background of communication - Chinese culture (foreign language expression) is still in a state of neglect. Colleges and universities basically did not put the traditional Chinese culture as an organic part into the teaching plan, the traditional cultural factors on the import of lack of consciousness, planning and systematic. Taking the teaching program of English undergraduate in 2015 in a foreign language university as an example, the number of courses in Chinese culture is only 54 , accounting for $7.5 \%$ of 
the elective course (702), accounting for $1.93 \%$ of the total class (2800). Non-foreign language major is almost no traditional culture curriculum be taught.

\section{B. Neediness}

With the deepening of the degree of internationalization of colleges and universities, more and more teachers and students have the opportunity to study abroad or take the part of exchange program, meanwhile more and more foreign students swarm into the Chinese universities campus. However, due to the lack of foreign language education in the teaching of Chinese culture, there are many obstacles in the international exchanges (mainly to understand the obstacles), and even negative effects. Therefore, there is a strange phenomenon in cross-culture, foreign students will be interested in traditional Chinese culture, and often asked such as Confucius, Mencius, Bagua, Qigong and other aspects of the Chinese culture. But the fact is that most of the Chinese students who are major in foreign languages even some foreign teachers can not give a satisfactory answer to foreign students. The cross-cultural communication become a negative impact between the foreign students and Chinese students. Meanwhile, our visiting teachers and our Chinese students who study abroad, would like to introduce Chinese culture and found it is difficult to express clearly, reflecting the ability to communicate severely restricted. According to a foreign language university survey in Zhejiang Province, more than $85 \%$ of the surveyed students understand and can introduce foreign festivals and writers in foreign languages. Only $30 \%$ of students can introduce Chinese special food and traditional festivals. On the Chinese characteristics of customs, moderation and other more complex explanation is basically low number of students can be introduced. [Yang Yong, He Xuejing, 2008]

\section{Integration}

In the internationalization of education, most of foreign languages universities are tend into making some cooperation with foreign universities, such as " $2+2$ ", " $3+1$ " and " $2+\mathrm{N}$ ". Chinese and foreign colleges and universities work together such as credits, curriculum, teaching standards and other mutual recognition, which makes the domestic and foreign academic identity tends to be consistent. However, in this trend, not only faced with the "localization" and "internationalization" of the degree of integration between the teaching, but also face the collision between Chinese and Western culture how to do the problem of integration. Widdowson [1983] "Language learning is necessary to establish learning purposes, and most of the learning language is intended for communication, especially intercultural communication, which is a two-way rather than one-way communication, which means that it is indispensable." Therefore, foreign languages universities can not blindly or completely accept the foreign ideas and knowledge, but should have a choice, to distinguish, according to the actual situation of colleges and universities [4].

\section{AN ANALYSIS OF THE OBSTACLES TO THE INFLUENCE OF CHINESE TRADITIONAL CULTURE IN THE FOREIGN LANGUAGES COLLEGES ON IN THE CONTEXT OF INTERNATIONALIZATION}

\section{A. The Dissemination of Traditional Culture in Foreign Language Textbooks}

The cultural orientation of textbooks in foreign languages education largely determines the cultural orientation of foreign languages education. The preparation of foreign languages teaching materials directly affects the implementation of teaching content and the realization of teaching purpose [Zhao Caihong, 2010] In the implementation of teaching, teachers even have the awareness of cultural teaching, but "teaching materials to teach" is a typical teacher's cultural orientation, teachers can do the successful implementation of traditional culture teaching, mainly based on the content of teaching materials.

To English teaching, for example, we can find that China's undergraduate college mainly use four kinds teaching materials in the foreign languages universities:

The first one is the Shanghai Foreign Language Education Press published in 1997, "College English Intensive Reading", 1-4 volumes of text almost no one related to the Chinese culture.

The second is the "College English (new version)" published by Shanghai Foreign Language Education Press, from four books, we know that Chinese culture is only part be mentioned, which is of a Chinese and Western learning style of different articles.

The third is the Foreign Language Teaching and Research Press published "new vision of college English: reading and writing tutorial" [2003]. Four of the four books related to Chinese cultural knowledge, respectively, for the traditional Chinese marriage, Chinese civil war, the Chinese city style and the ancient Chinese earthquake prediction method.

The fourth is Zhejiang University published "New College English" [2002]. This is the four sets of teaching materials involved in Chinese culture, the most knowledge of a set of teaching materials, mainly introduced the characteristics of Chinese food, cooking methods, the Chinese bridge culture, the Chinese hospitality, "Journey to the West" Monkey King and comparative analysis of the West The way of learning is different.

Through the analysis, we can see that the emphasis on the content of Chinese culture in college English textbooks has been deepened, and gradually realized that the spread of Chinese culture in English teaching is important, but the proportion of content is still very low, but also mainly in the Extensive and after-school exercises. Students input to the Western culture or the main content. Because of the lack of Chinese cultural content in the teaching materials, students can not learn the Chinese concept in English, tell the contents of Chinese culture, and export the essence of Chinese culture, so that cultural aphasia is easy in intercultural communication. 


\section{B. The cultural awareness of the situation of Students and Teachers}

In the tendency of globalization, college students face all kinds of cultural confusion and challenge, and some values of traditional culture will be changed [5]. Language is the carrier of culture, foreign language teaching is not only pure foreign language knowledge, but also with the economic development, cultural transmission, political process and so on.

Foreign language teaching in the deep, multi dimensional impact of the individual education of the mother's attitude towards the mother tongue culture. The results show that most students can not use English to express Chinese culture well. The larger part is an interpretative translation. Liu Jing [2007] survey found that $30 \%$ and $30.4 \%$ of college students admitted that "their understanding of traditional culture is not enough" to accept the influence is not enough. Ji Jingtong and Song Li [2015] conducted a survey on the ability of English students to express English culture in English. The results showed that the results of English and American culture expressed in English were 29.42\% higher than those in English. These subjects indicate that the main focus of the subjects is on the accumulation of foreign language knowledge and target language culture, and that the foundation of the Chinese culture is only established in the unconscious and is fragmented and non-systematic. At the same time, the daily teaching input for foreign language knowledge and culture, dilute the Chinese knowledge and culture.

At the teacher aspect, foreign languages teachers not only bear the task of languages teaching, but also bear the task of cultural communication. Teachers need to guide students through the emotional, fragmented cultural phenomenon rose to a systematic, rational cognitive height. Deng Wenying and Ao Fan [2015] conducted a questionnaire survey of 50 foreign language teachers in 10 colleges and universities in Sichuan Province. It was found that there were some deficiencies in the expression of foreign language teachers in Chinese culture. In the analysis of reasons, the teacher himself admitted that China's cultural knowledge is a low of $20 \%$, textbook design of Chinese cultural information accounted for $30 \%$ less, $35 \%$ of the test is not designed, and students are not interested in $35 \%$. These instructions teachers only concerned about the teaching materials and examinations, blindly follow the examination and teaching materials, passive acceptance of what materials on what to teach, what to test what to test what, while ignoring the strengthening of their own knowledge of Chinese culture and a clear understanding of the lack of awareness Effective guidance of student interest.

\section{Traditional culture in foreign languages testing}

At present, the content of foreign language testing is still largely focus on the target languages culture teaching. By the influence of "utilitarianism" thought, many teachers think that the necessity of teaching foreign language knowledge in Chinese culture is far from the necessity of foreign language culture, and concerning the examination involves less content, it has little effect on students' improvement of foreign language achievement. Although since December 2013 of CET 4, CET 6 , the translation part of the original sentence translation changed into paragraph translation, which means Chinese culture as the test point be mentioned and the content cover from the Chinese campus culture, social life, food and entertainment, science and technology development, and Chinese traditional culture. To some degree, it will strengthen the foreign language teachers on the Chinese cultural knowledge in teaching, and for the students, can enhance the opportunities to contact the Chinese culture of foreign language information. However, in the daily life, students is of weak cultural awareness and have positive attitude toward to the teaching materials involved in the Chinese culture foreign language vocabulary or Expression and it is difficult in a short time to effectively improve.

\section{OPTIMIZING THE STRATEGY OF TRADITIONAL} CULTURE COMMUNICATION IN FOREIGN LANGUAGE COLLEGES AGAINST THE BACKDROP OF INTERNATIONALIZATION

\section{A. Teachers to cultivate the direction: to enhance cultural intelligence}

Julia Middleton put forward the concept of "cultural intelligence" and point out that "cultural intelligence refers to the recognition ability, adaptability and competency reflected by individuals in unfamiliar environment [2014]. It reflects the collection and processing of information in the new intercultural background. To make judgments and take effective measures in the globalized world, cultural intelligence is the most important part of the competitiveness of cross cultural workers.

Internationalization of the trend of colleges and universities, the most important carrier of cultural intelligence is responsible for teaching and cultural exchanges of foreign language teachers. Foreign languages teachers are the main focus on cross-cultural communication in foreign language teaching, which directly determines the quality of crosscultural communication. Therefore, this requires teachers should not only have a profound language skill, but also must have a high cultural accomplishment and strong cross-cultural awareness and expression in foreign languages and the quality of Chinese culture. To guide students to establish a sense of equality of cultural exchanges, to cultivate students' tolerance of different cultures, teachers are required to continuously enhance their own business ability, in-depth the study of Chinese and foreign knowledge, explore the cultural essence, to expand the cultural aspects of research, enhance their overall quality of Chinese and Western culture, improve their own culture of foreign language expression. At the same time, it also requires colleges and universities to improve the mechanism, develop some training requirements and standards, train a group of young and middle-aged teachers' groups which is of Chinese accumulated deep, foreign solid foundation, international vision of, and actively impart and disseminate Chinese culture. 


\section{B. Teaching content adjustment: to overcome the one- dimensional thinking}

First of all, we must follow the principle of resonance. Resonance strategy derived from marketing, refers to the operator through the cause of consumer resonance, so that consumers can get a greater degree of satisfaction, so as to enhance their image and competitiveness [6]. The resonance strategy is of great significance to cross-cultural communication. As the cross-cultural communication between the two sides have different cultural background, values, ways of thinking and interest concerns. Communication must cross a wide range of obstacles, to achieve the communication between the communicator and the audience to achieve the desired communication effect. In foreign languages teaching, teachers should follow the principle of resonance, need to find the combination of Chinese culture and target languages culture. Teachers need to adjust the dissemination of Chinese cultural contents so that students can understand the core concepts of Chinese culture and modern values, rather than just a few words introduced.

Second, follow the principle of reciprocity. Culture is an interactive existence, to comply with the "reciprocal understanding" that is in the dialogue and cooperation beyond the cultural bias and beyond the other's culture as a knowledge of understanding and interest to meet the limitations in order to build healthy, benign cross-cultural communication. Therefore, we must strengthen the interaction between Chinese culture and foreign culture. On the basis of cultivating the foreign languages application ability of "listening, speaking, reading and writing", we must expand the goal of cultural communication ability, integrate it into Chinese culture content in foreign languages teaching by comparing the similarities and differences of intercultural communicative competence [7].

Finally, follow the "harmony but not sameness" principles. Different countries and different cultures have their own cultural values, ideologies and values. Although integration and conflict are the main melody in the field of cross-cultural communication, but integration is the ultimate goal of conflict. Therefore, college teachers and students should adhere to the correct cultural attitude under the internalization. We should have the right attitude towards Chinese culture, rather than selfish, blindly exaggerate or worship the language of the essence of national culture. To learn the language of the target language at the same time, we should actively spread the Chinese culture, through the "harmony and different" ideas, objective and rational analysis of foreign culture, absorb the essence of foreign culture.

\section{Communication means change: a variety of media intervention}

With the "Internet age", students get knowledge of the place is not tightly confined to the classroom, more and more students tend to "move learning", "smart learning". The scope of learning is derived from the first classroom to the second class or even the third class. Therefore, we have to grasp the status of students using the media and targeted use of new media, such as the creation of Chinese culture as the theme of microblogging, WeChat public number, so that students use the fragmented time for effective learning. We also can organize various traditional Chinese cultural community activities or seminars, inviting foreign students, foreign teachers to participate in the second and third classroom activities. By carrying out the spread of traditional Chinese cultural knowledge, it can improve the students' understanding of Chinese culture, to improve the comprehensive use of foreign languages ability and cross - cultural communication abilities.

\section{CONCLUSION}

It can be seen that the dissemination of Chinese culture in foreign languages undergraduate students occupy an important position. Therefore, foreign languages colleges and universities not only strengthen the language teaching, foreign languages education personnel training, but also we should pay attention to cross-cultural communication. The universities should not only focus on cultural knowledge and theoretical conservation, but also to cultivate cross-cultural communication background of Chinese culture needs the practice and application of the ability.

This is the big issue how to adapt to the new situation and do a good job of language and cultural communication in the background of the country's "one-belt" strategy. Therefore, the colleges and universities have a long way to go. We should do a good job in training foreign language talents, at the same time, we also need to focus on the model research and practice of macro-training.

\section{ACKNOWLEDGMENT}

This research was supported by the 2016 The program of Teaching Reform in Higher Education in Shaoxing. And The program of 2017 Chinese Culture Research Centre (ZWHA201701)

\section{REFERENCES}

[1] H.G. Widdowson: Learning purpose and Language Use [M]. Oxford University Press, 1983.

[2] Zhao Caihong : English Education and the Transmission of Chinese Excellent Traditional Culture [M]. Shandong Friendship Press, 2010.

[3] Middleton, Julia. Cultural Intelligence [M]. A\& C Black Publishers Ltd, 2014.

[4] Deng Wenying,Ao Fan : An Analysis of Chinese Cultural Aphasia in English Majors [J].Journal of Bingtuan Education Institute,2015(4).

[5] Ji Jingtong,Song Li : Problems and Reflections on Chinese Cultural Input in College English Teaching[J].Sino-US English teaching, 2015(2).

[6] Liujing: An Investigation on the Influence of Foreign Fashion Culture on Contemporary College Students [J]. Journal of Guangxi Youth Cadre College, 2007 (5).

[7] Yang Yong, He Xuejing : Research on the Chinese Culture Teaching in English Cultural Education [J]. Journal of Chengdu University, 2008(2). 